\title{
Social Responsibility of Service Design in Present China
}

$$
\text { Yuhong } \operatorname{Han}^{1, a} \text {, Cheng Hong }{ }^{1, b} \text { and Jing } \mathrm{Li}^{2, \mathrm{c}, \text { * }}
$$

${ }^{1}$ College of Architecture \& Urban Planning, Beijing University of Technology, Beijing, 100124, P. R. China

${ }^{2}$ College of Applied Sciences, Beijing University of Technology, Beijing, 100124, P. R. China

\author{
ahyhlux@163.com, bhc_bj@outlook.com, ${ }^{\mathrm{C}}$ leejing@bjut.edu.cn \\ * Corresponding Author
}

Keywords: Service Design, Social Responsibility, Economic Transformation, Smart City

\begin{abstract}
This paper, taking an emerging design discipline of "Service Design" as a starting point, combined with contemporary social phenomenon and the development trends of China, discussed the social responsibility and development of Service Design in present China from five aspects, including Service Design drives social and economic transformation, Service Design with big data, Service Design help construct smart city and improving people's livelihood and well-being of the public service platform, the necessity of Service Design education. With the continuous research of Service Design, it will become the driving force of innovation and development of our society.
\end{abstract}

\section{Introduction}

Service Design is an emerging design discipline. With the evolution of present life style and development of technology, Service Design attracts people to explore with more interests [1]. Service Design is commonly considered different from other design thinking including how to design, how to implement and how to transfer the thinking mode for design object to thinking mode for design service. Social responsibility of Service Design in present China shall be based on combination of humanity, existence and development, and how to be human-centered and establish environment of human experience to meet demands for users.

\section{Service Design Drives Transformation from “Product Economy” to "Service Economy”}

What is Service Design? It is an emerging noun and a new professional discipline in contemporary design field. In the book Design Management Systems “Service Design" is defined as a service shape stage. It normally coincides with customers' reasonable and potential demands that can be expected. It can also use available resources economically [2] [3]. Service Design needs to cooperatively realize co-creation and cooperation cross disciplinary and department in integration of many fields, and Service Design itself is an activity that needs everyone to participate in and cooperate jointly [4].

As one kind of design thinking mode, Service Design creates and improves service experience for human. At the time of emphasizing excellent design result, it pays more attention to all kinds of excellent experiences given to people in the process of service, and good vision for development can be realized through this experience. China, as the world's biggest manufacturing country, manufacturing, known as the backbone of real economy of one country. In case that there is no support of manufacturing, Internet economy will lose foundation for existence and development. Therefore, it is difficult to sustain mainly depending on increasing mode for extensive economy of resource element input and scale expansion.

Industry division cooperation continuously deepens in the process of industrialization, and it facilitates service transformation of manufacturing. Service manufacturing is the necessary requirement for strengthening industry competition and pushing manufacturing from big to strong. Service economy is new industry form of integrative development for manufacturing and service, 
and important direction for transformation and upgrading of manufacturing. Our country also embraces rare chance for global synchronized innovation, and further advance for "China Manufacturing plus Internet" provides broader development space and stronger technology for service manufacturing. Coordination and integration for manufacturing shall be quickened, and value chain for manufacturing can be remolded to cultivated new energy for the industry [6] [7].

"Green design" is the first lever to promote green development and an important support for providing lateral structure reform. As an important mean, mode and method to govern environment pollution and respond to increasing shortage for energy resource from the origin, green design is generally known by the public. Service manufacturing is an important measure to effectively improve supply system and adapt to updating of consumption structure. China shall take a path of green development, low-carbon development and cyclic development.

\section{Combination of Service Design with Big Data to Explore New Model of Intelligent Service}

1) Service Design is aimed at transforming from a provider of plans to the thinking and method of joint participation in the practice of launching

How to guide manufacturing enterprises to conduct cross-domain and cross-region collaboration, establish cooperative organizations of industrial chain such as big data alliance to have access to multiple resources such as science, finance and culture [8]? How to conduct deep participation in industrial and social collaboration? How to strengthen the policy guidance of mass entrepreneurship and innovation and "internet plus", make full use of the service platform such as crowd innovation, crowd support, crowd sourcing, and crowd funding etc. to promote the integration and interaction of maker, public service, consumer and enterprises? How to promote the popularization of the sharing economy and create an ecological environment that is conducive to the development of the service-oriented manufacturing innovation to promote new services? The coming of the big data age makes the world well-rounded and many irrelevant things starts to show relation with each other. For many things, it becomes quite easy to plan or solve for the coming of big data.

In the big data age, there is rich and mass information behind the multifarious data and the big data age makes more information hide in a deeper level and in an unacquainted way. A research group of Harvard University has proposed a famous concept of Resource Triangle: without matter, nothing would exist; without energy, nothing would happen; without information, nothing would make sense. Matter, energy and information differ from each other. They are the three essential bases with which the human society can survive on and develop: the world is made up of matter; energy is the impetus for the matter; information is the evidence that the human being gets to know the nature and the human society. Therefore, how to accurately obtain information has become a topic worth exploring in the big data age.

2) To exploit data resources of big data through the Service Design thinking. The word "data" means "known" in Latin, and can also mean "facts".

Through analysis, we find that the application circumstances of the data of enterprises today include the following six aspects.

(1) Integration with data origin. Only having Microblog data, forum data, advertising data and research data is useless, even if you have the forefront Wechat data. Cross analyzing and proposing of data integration is a definite trend.

(2) Integration with CRM. Currently, the listening nature of socialization enables us to obtain the insights of customers. These data and insights are used to cross-contrasted with the CRM data of enterprises or to enlarge and optimize the CRM resource of enterprises to form life management of CRM data of enterprises.

(3) Command center of data. It's a real-time system and the data can be visually presented throughout the year of 365 days and the day of 24 hours, which clearly shows the active follow-up for market change. This is how the command management is made.

(4) To be used in Old-brands of BI and ERP. Old-brand informatization manufacturers will not miss the opportunity brought by the socialized media age and a new data module of BI and ERP is 
on the way.

(5) Analysis of creation of power and influence. This is an industry where one needs certain spread knowledge and practice for comprehensive development and if with particular algorithms and specific knowledge. This industry will also bring many surprises or amazements.

3) To solve problem through the Service Design thinking and big data analysis.

(1) In 1923, Arthur Charles Nielsen, one of the founders of the modern market research industry, established AC Nielsen Company in America. Among all the innovations about customer-focused marketing and media research, Mr. Nielsen invented retail measuring technique which provides reliable and impartial information for the customer to know how its business performance and the marketing activity influence the income and profit. This is an example of applying data to help the action of decision-making.

(2) An enterprise of Los Angeles claims that they modeled the data of the night scene all over the world and got the research report for real estate investment and consumption after filtering the fluctuations. McDonalds can acquire the accurate address of users when selling hamburgers by delivery services. These collected addresses become a fantastic internal data of real estate industry. Data of logistics company only served for the needs of operations (such as optimal dispatching of the internal fleet), but when used again, logistics company becomes financial company and the data is used for evaluating the credit of customer. Then they provide mortgage for free or payments for goods that are being delivered as pledge! These are successful examples showing that seemingly useless big data can yield significant benefits. In the application of big data, we also see the risk of hidden danger of "The Arrogant Trend of Big Data”.

\section{To Construct Smart City Through the Service Design Thinking}

Service Design is to construct smart city that integrates digitization, networked, intelligent and interconnected in the process of the construction of smart city and the origin of force is focused on society, environment, management and the quality of citizen's work and life. How to use Service Design and promote social reform is to integrate government functions, urban management, service of the people's livelihood and business economy through the big platform of smart city [9]. China becomes the biggest experimental and practice base due to its specific economic, social and historical background. This does not exist in other western countries. How to shoulder the important task of the development during China's social transformation period? It has both challenges and opportunities.

From the perspective of the Service Design thinking, we should focus on the orderly traffic, green constructions, good water treatment technology, intelligent power supply system, smart home, smart city, the role of government and service economy etc. in the current and future context. Service Design will in what way transform from a provider of plans to the thinking and method of join participation in the practice of launching to construct a city that features green and sustainable development.

To construct smart city through Service Design thinking has transcended the level of technology and simply "matter" and is more of humanistic care; it's not only a progress of design philosophy, but also a demonstration of the value on beauty and virtue and morality all the more.

\section{Improve People's Livelihood and Social Welfare by the Public Service Design that Benefit People and Construct Public Service Platform for Innovative Design}

1) Human-centered, people's livelihood as a starting point, centering on community services, carry out intelligent application of fields such as intelligent community and home-based care for the aged etc [10].

Service Design should play a role in the aspects of environment of providing for the aged, service for life and development of well-being product etc. to advance the development of the well-being for Chinese aging; meanwhile, for the social civilization and progress, vulnerable groups 
should be paid more attention to: the vulnerable groups fall into two categories: physiological vulnerable group and social vulnerable group. The phenomenon of vulnerable groups is due to physiological and social reasons such as aging, disease, unemployment and being excluded etc. "Well-being"means more favored and happiness, which emphasizes that the people should feel happy. As aging becomes an irreversible global trend in the 21st century, constructing a humanized, high-efficiency and both flexible and interactive service system is an effective attempt for now and future. At the same time, by leveraging all different levels of social resources should be combined with the Service Design philosophy to research the hierarchy of needs and characteristics of the well-being culture and the physical resources and non-physical resources for aged society. The rational thinking for the problem of the social well-being should be rendered through the comparative study based on the current national condition and the new emerging design field. Coping with aging should not only be the responsibility of national but also the common responsibility of all social forces.

2) To construct public service platform featuring innovative design by Service Design

Dr. Sabine Junginger of Danish design, culture and management research center points out that in management of public affairs, Service Design is focused on the service itself and all its intertwined relationship with the insider and outsider of the organization system and the organization flow, planning and service system. Public Service Design can play an effective role in the following three aspects: one is that public Service Design can help government sectors to reconsider the method of working and the attitude towards reality from user's point of view; second is that the concept of Service Design can assist the government to conduct the test and simulation work before the government invests significantly and can effectively reduce and avoid the risk of decision-making; third is that Service Design can help the public functional departments of the government to establish new value consciousness and provide the way to solve problems aiming at the needs of the future [6].

Public Service Design involves domains such as social security, compulsory education, employment service, medical treatment and public health, communal facilities and civic rights etc.; Service Design can play a role as the think tank of government sectors and provide the prediction model of the lowest cost. Service Design thinking can assist the government sectors to rethink the method of working and the attitude towards reality from the user's point of view. It can assist the government to conduct the test and simulation work before the government invests significantly and can effectively reduce and avoid the risk of decision-making; it can assist the public functional departments of the government to establish new value consciousness and provide the way to solve problems aiming at the needs of the future.

Based on the analysis of the mechanical theory as the foundation, designed the soccer robot pick the ball institutions optimal design process, found aim function, select design variables and the corresponding optimization algorithm to optimize a complete set of institutions. At last through the test to get the final performance parameters of the institution. Experiments show that the system has higher accuracy and stability, the new optimize pick the ball have design basic requirements, and achieved good ideal control effect.

\section{Improve Promotion of the Development Mission for the Education of Service Design}

Human-centered, people's livelihood as a starting point, centering on community services, carry out intelligent application of fields such as intelligent community and home-based care for the aged etc. Service Design covers many disciplines and fields. Sophisticated Service Design major has been set up in countries with development history of more than decades like America, England, Italy, German, Denmark and Finland etc. They also set up research institute of Service Design facing the innovation of management of public affairs. The research on Service Design has come relatively later in our country. Among colleges and universities such as Jiangnan University, Tongji University, Zhejiang University, Tsinghua University, Hong Kong Polytechnic University and Beijing University of technology etc. are all setting up relevant courses and specialized research 
concerning with Service Design. The relatively early setting up of Service Design course is by the team led by Deputy Professor Gong Miaosen of Jiangnan University. They carried out the research on Service Design and establish network sharing platform which is "Service Design in China", which features its own educational philosophy of enhancement, practicability, innovation and exploration. (www.servicedesignchina.org) shows the academic quality of communication and sharing.

The good news is that Ministry of Industry and Information Technology joined hands with Beijing University of Technology to establish Service Design Development Research Center of China which will serve the cultural creative industry of capital Beijing and promote the fast development of the service economy of China. It will guide the domestic Service Design industry and be committed to deep integration of government, enterprises, education, research institutes. The cooperation between the government and colleges on research of national major projects will promote the transformation from China manufacturing to China creation, from China speed to China quality and from China product to China brand which will promote modernization construction and fast development of Chinese service economy. Service Design of China is now proactively responding to the challenges of high-level Service Design in the world and at the same time all opportunities for innovation and development arise from its ascent.

\section{Conclusion}

The further promoted "China manufacturing plus Internet" provides broad space for development and strong technical support for the service-oriented manufacturing. Transformation from simply selling product to selling "product with service" and developing of service-oriented manufacturing are inevitable requirement for strengthening industrial competitiveness and promoting manufacturing industry from big to strong, and the initial selection for conforming to a new round of scientific and technological revolution and industrial transformation. We should have the whole world in view and pay attention to gain excellent experience of contemporary western Service Design. Service can increase actions, promote the development of innovative design as an important bridge, promote the transformation from China manufacturing to China creation, from China speed to China quality and from China product to China brand.

\section{References}

[1] Herbert A. Simon, The Sciences of the Artificial [M], 3rd Revised Edition, MIT Press, 1996.

[2] Lavrans Lovilie, Chris Downs, Ben Reason, Bottom-line Experiences: Measuring the Value of Design Service[J], Design Management Review, 19(1), 2008.

[3] Roberto M.Saco, Goncalves, Service Design: An Appraisal, Design Management Review, 19(1), 2008.

[4] Marc Stickdorn, Jakob Schneider. This is Service Design Thinking: Basics, Tools, Cases[M], John Wiley \& Sons, Inc., New Jersey, 2011.

[5] Department of Informatization, National Development and Reform Commission, Chinese Academy of Engineering, Special Action Guide of Development Service Manufacturing.

[6] Jegou. F., Manzini. E., Collaborative Services: Social Innovation and Design for Sustainability[M], Milano: Polidesign, 2008

[7] Wang, S. H. Williams, P. Shi, J. \& Yang, H., From Green to Sustainability-Trends in the Assessment Methods of Greenuildings[J]. Frontiers of Engineering Management, 2(2):114-121, 2015.

[8] Manzini. E, Design, When Everybody Design: An Introduction to Design for Social 
Innovation[M], Boston: MIT Press, 2005

[9] Guangming Daily, Construction Thoughts and Planning for Smart City with Chinese Characteristics October 12, 2015.

[10]Man Haixia, Research on the Supply of Providing-for-the-aged Public Services in China [J], Population Journal, 2013. 